\title{
Obesity, Renin-Angiotensin System Blockade and Risk of Adverse Renal Outcomes: A Population-Based Cohort Study
}

\author{
Jordana B. Cohen ${ }^{a}$ Alisa J. Stephens-Shields ${ }^{b}$ Michelle R. Denburg ${ }^{b, c}$ \\ Amanda H. Anderson $^{b}$ Raymond R. Townsend ${ }^{a}$ Peter P. Reese ${ }^{a, b}$ \\ ${ }^{a}$ Renal, Electrolyte and Hypertension Division, Department of Medicine, Hospital of the University of Pennsylvania, \\ ${ }^{b}$ Center for Clinical Epidemiology and Biostatistics, Perelman School of Medicine, University of Pennsylvania, and \\ 'Division of Nephrology, Children's Hospital of Philadelphia, Philadelphia, Pa., USA
}

\section{Key Words}

Angiotensin converting enzyme inhibitor $\cdot$ Angiotensin receptor blocker $\cdot$ Renin-angiotensin system blockade . Obesity · Hypertension · Chronic kidney disease

\begin{abstract}
Background: Obesity substantially increases the risk of the development of chronic kidney disease. Adipose tissue expresses all of the components of the renin-angiotensin system (RAS), contributing to the high prevalence of hypertension in obese patients and driving renal hyperfiltration and subsequent glomerular injury. Methods: We performed a retrospective cohort study using a United Kingdom primary care database, evaluating the effect of time-updated exposure to RAS blockade versus all other antihypertensive medications in obese, hypertensive, non-diabetic patients. We used Cox proportional hazards modeling with and without marginal structural modeling to assess the hazards of developing a primary outcome of $50 \%$ reduction in estimated glomerular filtration rate (eGFR) (across 2 consecutive values), end stage renal disease or death. Results: A total of 219,701 patients met inclusion criteria, with a median 7.2 years of follow-up. Median baseline eGFR was $72.6 \mathrm{ml} / \mathrm{min} / 1.73 \mathrm{~m}^{2}$. Compared to other antihypertensive medications, patients
\end{abstract}

treated with RAS blockade had a modestly elevated hazard of adverse renal outcomes using traditional Cox regression (hazard ratio (HR) 1.04, 95\% Cl 1.01-1.07) and no significantly increased hazard by marginal structural modeling (HR $1.02,95 \% \mathrm{Cl}$ 0.97-1.08). Patients treated with RAS blockade had a significantly reduced hazard of incident diabetes, but no significant difference in mortality. Conclusion: This study, conducted in a large real-world cohort, provides evidence that RAS blockade may not provide benefit with regard to longitudinal renal outcomes in obese, hypertensive patients. Further research is needed to elucidate the hemodynamic and renoprotective role of antihypertensive medications in obese patients.

(c) 2016 S. Karger AG, Basel

\section{Introduction}

Obesity is a critical public health issue in the United States (US) and other developed countries. According to the 2011-2012 National Health and Nutrition Examination Survey, $34.9 \%$ of adults in the US are obese, a substantial increase in prevalence from $22.9 \%$ in the 1988 1994 survey $[1,2]$. Correspondingly, the Health Survey for England in 2013 reported that 26\% of men and 24\%

\section{KARGER}

E-Mail karger@karger.com

www.karger.com/ajn (c) 2016 S. Karger AG, Basel

$0250-8095 / 16 / 0436-0431 \$ 39.50 / 0$
Jordana B. Cohen, MD, MSCE

Renal, Electrolyte and Hypertension Division, Department of Medicine Hospital of the University of Pennsylvania

3400 Spruce St., 1 Founders, Philadelphia, PA 19104 (USA)

E-Mail jco@mail.med.upenn.edu 
of women in the United Kingdom (UK) population are obese, an increase from $13 \%$ of men and $16 \%$ of women in 1993 [3, 4]. Obesity significantly elevates the risk for development and progression of chronic kidney disease (CKD) [5-10]. Much of the heightened risk of CKD in obese patients is attributable to the close link between obesity and the other components of the metabolic syndrome [11-14]. In particular, type 2 diabetes and hypertension account for the majority of CKD cases in the US [15]. However, obesity is also a potent independent risk factor for the development of CKD and end-stage renal disease (ESRD) [7-10]. In a retrospective cohort study of 320,252 patients linking the Kaiser Permanente database to the US Renal Data System registry, after adjusting for diabetes and hypertension, Hsu et al. [10] found a 3-fold magnified risk of incident ESRD in obese patients and a 5-fold increased risk of ESRD in severely obese patients (body mass index $(\mathrm{BMI}) \geq 40 \mathrm{~kg} / \mathrm{m}^{2}$ ) compared to normal weight individuals.

The renin-angiotensin system (RAS) is closely linked to the development of obesity-associated kidney disease, which is typically characterized by an indolent rise in creatinine over several years and subnephrotic range of proteinuria. Kidney biopsies of patients with obesity-associated kidney disease demonstrate a type of focal segmental glomerulosclerosis, most notable for enlarged, often sclerotic glomeruli and subtotal foot process effacement of the podocytes $[16,17]$. These findings are driven by maladaptive changes that occur as a result of glomerular hyperfiltration [18]. Adipose tissue expresses all components of the RAS, including renin, aldosterone, angiotensinogen, angiotensin converting enzyme (ACE) and angiotensin II types 1 and 2 receptors [19, 20]. RAS activation causes afferent renal arteriolar dilation and efferent renal arteriolar vasoconstriction. As a result, each individual nephron is exposed to greater renal plasma flow, increased glomerular pressure and hyperfiltration, leading to glomerulomegaly, podocytopathy and focal glomerulosclerosis $[16,17,19-25]$. The podocytopathy, coupled with increased intracapillary pressure, often results in proteinuria $[17,25]$.

Patients who undergo surgical weight loss interventions may experience a reversal of renal hyperfiltration and reduction in proteinuria [26]. Correspondingly, a reduction in body weight of as little as $5 \%$ results in a clinically significant decrease in RAS expression, which may contribute to the reduction in hyperfiltration and proteinuria after weight loss [27]. RAS blockers (specifically ACE-inhibitors (ACE-Is) and angiotensin receptor blockers (ARBs)) are renoprotective in many types of
$\mathrm{CKD}$, particularly in the presence of proteinuria [28-32]. Obese patients are more sensitive to the hemodynamic effects of RAS blockade than normal weight individuals [33]. However, very little is known about the long-term effects of RAS blockade in obesity-associated kidney disease, and in particular, whether these effects are modified by proteinuria and baseline kidney function. The purpose of the study is to evaluate the effect of RAS blockade on the development and progression of CKD in obese patients.

\section{Methods}

Overview of the Study Design

We performed a retrospective cohort study using The Health Improvement Network (THIN). We assembled a cohort of obese, non-diabetic adults with treated hypertension, and compared time to development of adverse renal outcomes in patients treated with RAS blockade (specifically ACE-Is and ARBs) versus other antihypertensive medications.

\section{Data Source}

THIN is a large database of de-identified information collected in the routine care of patients by their general practitioner and recorded in the electronic health record. The database contains high quality information on 11.9 million patients from 578 practices throughout the UK, encompassing 80.9 million person-years of data [34]. The data contain demographics (excluding race), diagnoses, procedures, laboratory and radiology results, blood pressure, BMI, pharmaceutical history, hospitalization data, socioeconomic status and death certificate data. Notably, every patient in the UK must be registered with a general practitioner who coordinates all care, writes all prescriptions, including those recommended by specialists, and is informed of events in the patient's care (online suppl. methods; for all online suppl. material, see www. karger.com/doi/10.1159/000446862) [34]. The study was approved by the THIN Scientific Review Committee; the Institutional Review Board of the University of Pennsylvania determined that the study met eligibility criteria for institutional review board exemption authorized by 45 CFR $\$ 46.101$, category 4 .

\section{Subjects}

The cohort was restricted to obese patients (defined as a BMI $\geq 30 \mathrm{~kg} / \mathrm{m}^{2}$ ) with treated hypertension (defined by the presence of at least one diagnostic code for hypertension and a minimum of 2 consecutive prescriptions for any antihypertensive medication). For each patient, we determined an index date that was defined as the earliest date at which that individual was (a) identified as both obese and hypertensive, (b) registered with a THIN practice for a minimum of 6 months and (c) had a serum creatinine measurement (online suppl. fig. 1 and 2). The index date also had to be after the practice began using Vision software and the patient death files were merged with other records in the database [35]. Patients were also required to have a baseline estimated glomerular filtration rate $(\mathrm{eGFR}) \geq 30 \mathrm{ml} / \mathrm{min} / 1.73 \mathrm{~m}^{2}$ by the CKD Epidemiology Collaboration (CKD-EPI) formula [36]. The eGFR incorpo- 
rates age (updated over the course of the study), creatinine, gender and race. The THIN database does not have ethnicity data available; thus, due to the low proportion of the population of African descent in the UK (3\%) [37], patients were assumed to be of nonAfrican descent for the purposes of the eGFR calculation.

Patients were excluded if they had a diagnosis code for type 1 or 2 diabetes mellitus prior to the index date or diagnostic codes for polycystic kidney disease, congenital kidney disease, urinary reflux, vasculitis or systemic lupus erythematosus. The earliest index date in the cohort was August 21, 1995; the latest date of follow-up was January 13, 2013.

\section{Outcomes and Censoring Events}

The primary outcome was defined as a composite outcome of $50 \%$ reduction in eGFR (occurring across a minimum of 2 consecutive eGFR values), ESRD or all-cause mortality [38, 39]. ESRD was defined as a new diagnostic code for maintenance hemodialysis, peritoneal dialysis or kidney transplant. Patients were censored at the time of transfer out of the practice or loss to follow-up (defined as 18 months with no physician visits or prescriptions). For all patients, the follow-up time ended at the earliest instance of the primary renal outcome (i.e., 50\% reduction in eGFR, ESRD or all-cause mortality), the end of the study or withdrawal from THIN.

Variables and Covariates (online suppl. table 1)

We included the following baseline covariates in the model: age, gender, socioeconomic status (included in the database as the Townsend Deprivation Index [40], a categorical variable), cardiovascular disease (defined by diagnostic codes), congestive heart failure (defined by diagnostic codes), hepatitis B status (defined by diagnostic codes), hepatitis $\mathrm{C}$ status (defined by diagnostic codes) and BMI. Time-updated covariates that were incorporated into the models included systolic blood pressure (SBP), eGFR, diabetes status, number of antihypertensive medications [41-43] and use of mineralocorticoid antagonists [44-47]. Time-updated confounders were categorized at 6-month time intervals for each patient. When there were multiple measures of SBP during a given 6-month interval, the mean of the values was utilized $[48,49]$. When there were multiple measures of eGFR, the minimum value was utilized. If covariates were missing for up to 2 time intervals ( 1 year), they were carried forward from the previous available time interval.

Secondary analyses included stratification by baseline CKD status (with CKD defined as eGFR $<60 \mathrm{ml} / \mathrm{min} / 1.73 \mathrm{~m}^{2}$ ) and by baseline proteinuria (defined as the presence or absence of an estimated equivalent to $\geq 300 \mathrm{mg} / \mathrm{g}$ proteinuria by urine dipstick, urine microalbumin or urine protein to creatinine ratio) [50] in the $26 \%$ of patients in whom proteinuria data were reported [29$32,51]$. Waist circumference was omitted from the models, as it was commonly missing from the data set $(<15 \%$ reported).

\section{Statistical Analysis}

Statistical analyses were performed using STATA version 13.0 (StataCorp LP, College Station, Tex., USA) with 2-sided hypothesis testing and $p$ value of $<0.05$ as the criterion for statistical significance. Descriptive statistics (mean, median and proportion) were used to describe baseline clinical and demographic characteristics comparing patients being treated with RAS blockade at the index date and patients on any other class of antihypertensive medications. Continuous variables were compared using Student's t test or Wilcoxon's rank-sum test for non-normally distributed variables. Categorical and binary variables were compared using the chi-square test.

For the primary analysis, we compared outcomes of patients who were exposed to RAS blockade (ACE-I or ARB) versus any other class of antihypertensive medications. We also performed a new user analysis that excluded subjects who were already on RAS blockade at baseline to evaluate the effect of incident RAS blockade use on adverse renal outcomes. A secondary analysis was performed using diabetes diagnosis as the outcome, as previous data indicate that RAS blockade may be protective against the development of diabetes [52]. We performed the analyses using traditional Cox modeling as well as Cox modeling with marginal structural modeling.

\section{Cox Proportional Hazards Modeling}

Kaplan-Meier curves were generated and log rank testing was performed to assess for equality of survival distributions [53]. Cox proportional hazards regression was used to estimate hazard ratios (HRs) and 95\% CIs for the composite outcome associated with exposure to RAS blockade at baseline. For the multivariable-adjusted model, we selected variables a priori that were known to be risk factors for ESRD based on clinical judgment and previously published literature, as described above [40-47]. The proportional hazards assumption was assessed via Kaplan-Meier curves using $\log -\log$ plots as well as statistical testing and graphical displays based on the Schoenfeld and scaled Schoenfeld residuals.

\section{Marginal Structural Modeling}

Marginal structural modeling was performed to address the relationship between time-updated exposure to RAS blockade and development of the composite outcome in the presence of multiple suspected time-dependent confounders [54,55]. The marginal structural Cox model was fit by pooled logistic regression utilizing inverse probability weighting [54]. Stabilized inverse probability of treatment weights incorporated all the above-listed baseline and time-updated covariates [56]. Stabilized inverse probability of censoring weighting was also incorporated into the marginal structural model including all of the baseline and time-updated covariates. Weights were truncated at the 1st and 99th percentiles [56].

\section{Results}

\section{Cohort Assembly and Characteristics (fig. 1)}

Overall, there were $1,108,909$ patients with a diagnosis of hypertension and at least 2 prescriptions for antihypertensive medications in the THIN database. Of those, 432,428 had a BMI of $\geq 30 \mathrm{~kg} / \mathrm{m}^{2}$ during their follow-up history. A total of 219,701 patients met additional study criteria and were included in the cohort. After omitting baseline users of RAS blockade, 121,738 patients were eligible for the incident-user analyses.

For the overall cohort at baseline, median eGFR was $72.6 \mathrm{ml} / \mathrm{min} / 1.73 \mathrm{~m}^{2}$, median age was 61 years, median SBP was $146 \mathrm{~mm} \mathrm{Hg}$ and median BMI was $32.8 \mathrm{~kg} / \mathrm{m}^{2}$. 




Fig. 1. Assembly of the primary cohort from UK patients in primary care practices in THIN.

The median duration of follow-up was 7.2 years (interquartile range 4.8-9.3 years). Forty-five percent were treated with an ACE-I or ARB at baseline (table 1). Compared to those who were not on RAS blockade, patients treated with RAS blockade at baseline were more likely to be male ( 49 vs. $39 \%$ ), had slightly higher median SBP (147 vs. $145 \mathrm{~mm} \mathrm{Hg}$ ), had a higher eGFR (73.3 vs. 71.6 $\mathrm{ml} / \mathrm{min} / 1.73 \mathrm{~m}^{2}$ ) and a higher frequency of congestive heart failure (3 vs. $1 \%)$ and coronary artery disease (13 vs. $10 \%)$.

Over the course of the study, $79.6 \%$ of patients were treated with RAS blockade during at least one 6-month time interval, and $67 \%$ of patients were on RAS blockade for at least $50 \%$ of follow-up. There were 52,024 patients in whom proteinuria data were available ( $26 \%$ of the original cohort). Out of the entire cohort, 19,321 patients (8.8\%) developed the primary end point of $50 \%$ reduction in eGFR (confirmed by a minimum of 2 consecutive eGFR values), ESRD or all-cause mortality. For the primary end point, there were 16.7 events per 1,000 person years (16.6 per 1,000 person years in patients who were not on RAS blockade at baseline, and 16.9 per 1,000 person years in patients who were on RAS blockade at base- line). Median time to the development of the composite end point was 5.5 years among patients who were not on RAS blockade at baseline, and 4.7 years among patients who were on RAS blockade at baseline. There were 12.1 deaths per 1,000 person years (with equal event rates in both exposure groups). There were 3.7 adverse renal events $(50 \%$ reduction of eGFR confirmed with 2 values or ESRD) per 1,000 person years (3.6 events per 1,000 person years in patients who were not on RAS blockade at baseline, and 3.9 events per 1,000 person years in patients who were on RAS blockade at baseline). There were 2.2 patients who developed ESRD per 10,000 person years, consistent with the UK national incidence rates of ESRD [57]; 2.0 patients per 10,000 person years developed ESRD who were not on RAS blockade at baseline, and 2.6 patients per 10,000 person years developed ESRD who were on RAS blockade at baseline.

\section{Analyses of the Primary Outcome Using Multivariable Cox Proportional Hazards Models}

Patients treated with RAS blockade at baseline had a modestly increased hazard of developing the primary composite outcome (Kaplan-Meier estimate, fig. 2; log- 
Fig. 2. Kaplan-Meier estimate of renal survival for the primary cohort by baseline exposure to RAS blockade.

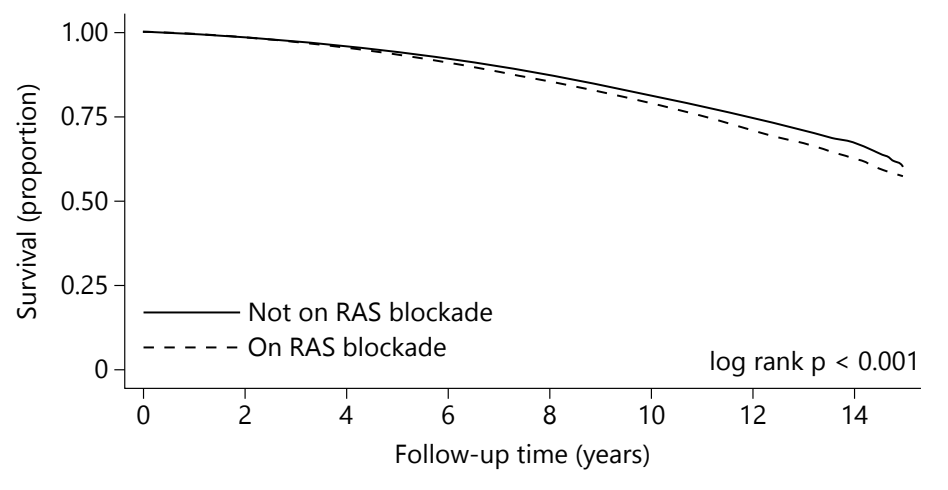

Number at risk

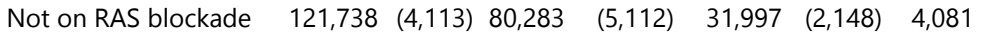

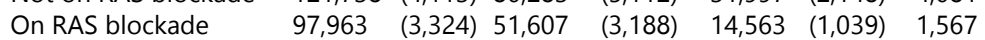

Table 1. Characteristics of baseline RAS blockade users vs. non-RAS blockade users

\begin{tabular}{|c|c|c|c|}
\hline $\mathrm{n}=219,701$ & $\begin{array}{l}\text { RAS blockade, } \\
\mathrm{n}=97,963(45 \%)\end{array}$ & $\begin{array}{l}\text { No RAS blockade, } \\
\mathrm{n}=121,739(55 \%)\end{array}$ & $\mathrm{p}$ value \\
\hline \multicolumn{4}{|l|}{ Patient demographics } \\
\hline Male & $62,933(49)$ & $35,327(39)$ & $<0.001$ \\
\hline Urban population & $81,827(64)$ & $59,929(66)$ & $<0.001$ \\
\hline Lowest socioeconomic quintile & $15,800(12)$ & $12,089(13)$ & $<0.001$ \\
\hline Waist circumference, $\mathrm{n}=30,245(13.8 \%), \mathrm{cm}$, median (IQR) & $109(102-118)$ & $108(100-117)$ & $<0.001$ \\
\hline SBP, mm Hg, median (IQR) & $147(136-160)$ & $145(135-160)$ & $<0.001$ \\
\hline Number of antihypertensives, median (IQR) & $1(1-2)$ & $1(1-1)$ & $<0.001$ \\
\hline$\geq 3$ antihypertensives & $9,462(10)$ & $2,657(2)$ & $<0.001$ \\
\hline $\mathrm{eGFR}, \mathrm{ml} / \mathrm{min} / 1.73 \mathrm{~m}^{2}$ & $73.3(60.8-86.9)$ & $71.6(60.4-84.1)$ & $<0.001$ \\
\hline Hepatitis $C$ virus & $58(0.1$ & $31(0.0)$ & 0.211 \\
\hline \multicolumn{4}{|l|}{ Baseline proteinuria data, $\mathrm{n}=55,963(26 \%)$} \\
\hline$\geq$ Microalbuminuria & $2,193(9)$ & $2,282(7)$ & $<0.001$ \\
\hline$\geq$ Macroalbuminuira & $291(1)$ & $273(1)$ & 0.002 \\
\hline
\end{tabular}

rank $<0.001$ and Multivariable model, table 2a; HR 1.04, 95\% CI 1.01-1.07). After stratifying by baseline CKD status, patients with baseline CKD had a significantly increased hazard of developing the primary outcome if they were treated with RAS blockade, but there was no significantly increased risk among patients without baseline CKD. The subgroup of patients in whom proteinuria data were available had a similar hazard of developing the pri- mary end point compared to the overall cohort; however, the sample size was smaller and the association was not statistically significant. There was no statistically significant association between exposure to RAS blockade and the primary outcome in each of the proteinuria subgroups.

In the incident-user analysis, patients had a significantly increased hazard of developing the primary out- 
Table 2. Effect of exposure to RAS blockade on the primary outcome (50\% reduction in eGFR over 2 consecutive values, ESRD or death)

\begin{tabular}{|c|c|c|c|c|c|}
\hline & \multirow[t]{2}{*}{ Patients, $\mathrm{n}$} & \multicolumn{2}{|c|}{ Multivariable Cox model* } & \multicolumn{2}{|c|}{ Marginal structural model ${ }^{\dagger}$} \\
\hline & & $\mathrm{HR}(95 \% \mathrm{CI})$ & $\mathrm{p}$ value & HR (95\% CI) & $\mathrm{p}$ value \\
\hline \multicolumn{6}{|c|}{ a Multivariable Cox model vs. marginal structural modeling } \\
\hline Overall & 219,701 & $1.04(1.01-1.07)$ & 0.021 & $1.02(0.97-1.08)$ & 0.447 \\
\hline$+\mathrm{CKD}$ & 52,637 & $1.08(1.03-1.14)$ & 0.001 & $1.08(1.00-1.17)$ & 0.050 \\
\hline$-\mathrm{CKD}$ & 167,064 & $1.00(0.96-1.05)$ & 0.826 & $1.00(0.92-1.06)$ & 0.729 \\
\hline Overall proteinuria subgroup & 55,963 & $1.04(0.98-1.11)$ & 0.195 & $1.03(0.93-1.13)$ & 0.577 \\
\hline+ Proteinuria and $+\mathrm{CKD}$ & 564 & $0.91(0.56-1.48)$ & 0.717 & $0.61(0.31-1.21)$ & 0.158 \\
\hline -Proteinuria and $+\mathrm{CKD}$ & 16,141 & $1.07(0.98-1.17)$ & 0.151 & $1.06(0.92-1.23)$ & 0.395 \\
\hline -Proteinuria and -CKD & 39,258 & $1.01(0.92-1.11)$ & 0.830 & $1.00(0.89-1.13)$ & 0.916 \\
\hline \multicolumn{6}{|c|}{ b Multivariable Cox model vs. marginal structural modeling; incident user design } \\
\hline Overall & 121,738 & $1.15(1.10-1.20)$ & $<0.001$ & $1.11(1.03-1.20)$ & 0.007 \\
\hline$+\mathrm{CKD}$ & 29,867 & $1.12(1.05-1.19)$ & $<0.001$ & $1.12(1.00-1.25)$ & 0.052 \\
\hline$-\mathrm{CKD}$ & 91,871 & $1.17(1.10-1.24)$ & $<0.001$ & $1.12(1.01-1.24)$ & 0.027 \\
\hline Overall proteinuria subgroup & 30,753 & $1.12(1.03-1.21)$ & 0.008 & $1.12(0.97-1.29)$ & 0.125 \\
\hline+ Proteinuria and $+\mathrm{CKD}$ & 273 & $1.23(0.65-2.33)$ & 0.519 & $0.54(0.22-1.35)$ & 0.189 \\
\hline -Proteinuria and + CKD & 8,754 & $1.09(0.97-1.23)$ & 0.166 & $1.15(0.92-1.43)$ & 0.212 \\
\hline -Proteinuria and -CKD & 21,726 & $1.12(1.00-1.26)$ & 0.046 & $1.13(0.94-1.35)$ & 0.211 \\
\hline
\end{tabular}

* RAS blockade usage and all other covariates are defined at the index date.

${ }^{\dagger}$ RAS blockade usage and covariates are time-updated. Marginal structural modeling uses stabilized inverse probability of treatment weighting, taking into account important time-updated confounders with regard to the likelihood of treatment at each time-point; this technique is analogous to using time-updated propensity scores, but takes into account previous confounders and treatment as well, facilitating causal inference $[54,55]$.

come if they were treated with RAS blockade (table $2 \mathrm{~b}$; HR 1.15, 95\% CI 1.10-1.20). There were 16.3 events per 1,000 person years in patients who were not treated with RAS blockade compared to 17.5 events per 1,000 person-years in patients who were treated with RAS blockade.

\section{Analyses of the Primary Outcome Using Marginal \\ Structural Models}

Patients had no significant association between exposure to RAS blockade and development of the primary outcome (table 2a; HR 1.02, 95\% CI 0.97-1.08), which persisted after stratifying by baseline CKD status and among the proteinuria subgroups.

In the incident-user analysis, patients had a significantly increased hazard of developing the primary outcome if they were treated with RAS blockade (table $2 \mathrm{~b}$; HR 1.11, 95\% CI 1.03-1.20) by marginal structural modeling. After stratifying by baseline CKD status, patients without baseline CKD had a significantly increased hazard of developing the primary outcome if they were treated with RAS blockade and a non-statistically significant increased hazard among patients with baseline CKD.

\section{Analyses of the Outcomes of Mortality and Incident Diabetes}

Treatment with RAS blockade had no significant effect on mortality (online suppl. table 2 ), but was significantly protective against development of diabetes using both modeling techniques (online suppl. table 3).

\section{Secondary Analyses}

Additional analyses were performed in which patients were censored for development of diabetes, rather than adjusting for development of diabetes, in the marginal structural models; the overall results were unchanged. In death-censored analyses, the results using both modeling techniques were similar to the composite outcome (online suppl. table 4). In analyses in which only a single eGFR value of $\geq 50 \%$ reduction from baseline was required to meet the composite renal end point, there was a significantly increased hazard of adverse renal outcomes in both the prevalent and incident-user analyses (online suppl. tables 5 and 6). To address the omission of race from the data set, subgroup analyses were performed using only patients who lived in geographic areas categorized in the lowest or highest quintiles of black population 
density; there was no significant effect of RAS blockade on adverse renal outcomes in each of the subgroups (online suppl. tables 7 and 8).

\section{Discussion}

Our study demonstrated no clear renal benefit to treatment with RAS blockade in obese, hypertensive patients. Furthermore, RAS blockade was protective against the development of diabetes, but not mortality. Little is known about optimal therapeutic interventions for the prevention and management of kidney disease in obese patients. This study is the first to specifically evaluate the effect of RAS blockade on long-term renal outcomes in obese patients with CKD and on the development of de novo kidney disease in obese, hypertensive patients on antihypertensive therapy. Additionally, using a large population-based dataset with detailed longitudinal data on medication use and blood pressure, this study employed the novel approach of marginal structural modeling to take into account the extent of time-updated exposure and time-dependent confounding present in this treatment setting.

Our findings of shorter time to the development of adverse renal outcomes associated with RAS blockade may be due in part to the intrarenal hemodynamic effects of these medications, as supported by the greater magnitude of adverse renal outcomes observed in analyses of incident RAS blockade users with or without CKD. Evidence suggests that obese patients experience greater hemodynamic response to RAS blockade than normalweight individuals. In an in vivo study monitoring the renal hemodynamics of 100 healthy, normotensive humans treated with captopril, Ahmed et al. [33] found that obese patients had a more marked renal vasodilatory response to short term ACE inhibition with captopril than normal-weight individuals $(\mathrm{r}=0.55$; $\mathrm{p}<$ 0.0001 ). This enhanced response to RAS blockade likely corresponds to the increased activation of the RAS in obese patients. Existing literature supports that the hemodynamic effects of RAS blockade may contribute to up to $30 \%$ acute, reversible reduction in eGFR $[58,59]$. Nonetheless, in our study, the outcome of $50 \%$ reduction in eGFR across 2 consecutive values or ESRD suggests that RAS blockade does not protect against chronic adverse renal outcomes in obese, non-diabetic patients compared to other antihypertensive agents [60]. Additionally, our study corroborates existing data that RAS blockade is protective against the development of diabetes, but not mortality in this patient population [52].

Our results should be considered in the context of prior studies. The Ramipril Efficacy in Nephropathy (REIN) trial was a double-blinded RCT comparing the effect of ramipril versus placebo in patients with non-diabetic, proteinuric nephropathies on the development of ESRD or doubling of creatinine. The REIN trial demonstrated a significant reduction in adverse renal outcomes in patients randomized to ACE-I therapy [31]. In a post hoc analysis of the 337 REIN trial participants with known BMI, Mallamaci et al. [61] found that there was a significant reduction in the rate of adverse renal outcomes over a mean of 30 months of follow-up in the 49 obese patients treated with ramipril compared to (1) obese patients treated with placebo (HR $0.21,95 \%$ CI $0.06-0.81$ ) and (2) normal-weight patients treated with ramipril (HR 0.18, 95\% CI 0.06-0.54). While the REIN post hoc analyses provided insight into renal outcomes in obese patients on RAS blockade, it is important to note that the patients in the REIN trial all had underlying proteinuria. Although RAS blockade is renoprotective in a broad range of kidney disease, there is no consistent evidence of renoprotective benefits of RAS blockade in patients without pre-existing proteinuria [62]. Our results in patients with proteinuria were inconclusive. Due to the low rate of ascertainment for proteinuria in the database, we had limited power to evaluate the effect of RAS blockade in patients with underlying proteinuria. Furthermore, the subset of patients in which proteinuria was measured may not be representative of the overall cohort, as there may have been confounding by indication for assessment of a urinalysis. Nonetheless, our study mainly addresses a different patient population than the REIN study, and suggests that RAS blockade may not provide enhanced benefit among obese hypertensive individuals without proteinuria.

Our study is strengthened by the use of marginal structural modeling (using stabilized inverse probability of treatment weighting) with Cox proportional hazards modeling to take into account the relationship between time-updated exposure and critical time-dependent confounders. Additionally, the use of an extremely large population-based database provides insight into the effects of hypertension treatment in a real-world setting, with broadly generalizable medical and socioeconomic risk factors that are analogous to other developed countries. The prevalence of both obesity and CKD in the UK, in particular, are comparable to the US population as well as many other European countries. However, the study participants are limited to the UK population, which reduces 
the degree of racial diversity compared to the US population.

In addition to limited data on proteinuria, our study is limited by the presence of other unmeasured confounders. THIN does not record information on race for individual patients, and information on smoking and family history are unreliably and inconsistently recorded. Therefore, these important confounders could not be included as covariates in the analyses. Furthermore, race could not be used in the calculation of eGFR. We attempted to address this limitation with subgroup analyses of patients in the lowest and highest quintiles of black population density, as presented in the online supplemental tables 7 and 8 . Also, due to limited clinical information about patients prior to cohort entry, confounding by indication remains possible. We attempted to address this issue in part by excluding patients with diabetes at baseline and adjusting for subsequent development of diabetes. However, we were unable to adjust for other factors such as hyperkalemia, angioedema and cough. We also acknowledge that classic eGFR equations have been criticized in obese patients due to the need to take into account large body surface area, misleading elevation in the eGFR due to hyperfiltration and difficulty estimating accurate muscle mass $[63,64]$. Attempts have been made to address this issue $[63,65,66]$. The CKD-EPI equation exhibits the least bias at higher levels of eGFR [36]. CKD status may still be misclassified based on the CKD-EPI equation. However, any potential bias should not impact within-individual changes in eGFR, and will be relatively consistent across all individuals, as our entire population was obese. Additionally, the CKD-EPI equation provides a standardized representation of kidney function as it is currently widely interpreted by the medical community [67]. Finally, the cohort experienced a limited number of ESRD events, limiting the study's power to examine this outcome. For all of these reasons, we have interpreted the findings cautiously and emphasize the need for additional studies to identify therapies that might offer renoprotection among obese patients.

In summary, in a large real-world cohort of patients, we did not find evidence that RAS blockade prevents adverse renal outcomes in obese, non-diabetic patients with treated hypertension. The outcomes shed light on the need to better understand the various potential contributing etiologies to the development of kidney disease in obesity, and how they interact with one another to result in adverse renal outcomes. Specifically, further research is needed to elucidate the hemodynamic role of RAS blockade and other antihypertensive medications in obese patients. Additionally, future epidemiological studies of antihypertensive agents among obese patients should examine important non-renal outcomes such as cardiovascular disease and diabetes.

\section{Funding/Support}

Research reported in this publication was supported by the National Institute of Diabetes and Digestive and Kidney Diseases of the National Institutes of Health under award numbers F32DK103484 and K23DK093556.

\section{Role of the Funder/Sponsor}

The National Institutes of Health had no role in the design, data management, analysis, preparation, review or approval of the manuscript. The content is solely the responsibility of the authors and does not necessarily represent the official views of the National Institutes of Health.

\section{Disclosure Statement}

R.R.T.: consultant/advisory board - Medtronic, Janssen, GSK, Merck.

\section{References}

1 Flegal KM, Carroll MD, Ogden CL, Johnson CL: Prevalence and trends in obesity among US adults, 1999-2000. JAMA 2002;288:17231727.

2 Ogden CL, Carroll MD, Kit BK, Flegal KM: Prevalence of childhood and adult obesity in the United States, 2011-2012. JAMA 2014; 311:806-814.

3 Boniface S, Bridges S, Craig R, Darton R, Fuller E, Hancock R, Henderson C, Knott C, Mandalia D, Mindell J, Moody A, Morciano M, Ng Fat L, Oyebode O, Robinson C, Sadler
K, Sutton R, Wittenberg R: Health Survey for England 2013: Adult Anthropometric Measures, Overweight and Obesity. Health and Social Care Information Centre, Leeds: Department of Epidemiology and Public Health, University College London, 2014.

4 Wang YC, McPherson K, Marsh T, Gortmaker SL, Brown M: Health and economic burden of the projected obesity trends in the USA and the UK. Lancet 2011;378:815-825.

5 Bonnet F, Deprele C, Sassolas A, Moulin P, Alamartine E, Berthezène F, Berthoux F: Ex- cessive body weight as a new independent risk factor for clinical and pathological progression in primary IgA nephritis. Am J Kidney Dis 2001;37:720-727.

6 Berthoux F, Mariat C, Maillard N: Overweight/ obesity revisited as a predictive risk factor in primary IgA nephropathy. Nephrol Dial Transplant 2013;28(suppl 4):iv160-iv166.

7 Manson JE, Skerrett PJ, Greenland P, VanItallie TB: The escalating pandemics of obesity and sedentary lifestyle. A call to action for clinicians. Arch Intern Med 2004;164:249-258. 
8 Iseki K, Ikemiya Y, Fukiyama K: Predictors of end-stage renal disease and body mass index in a screened cohort. Kidney Int Suppl 1997; 63:S169-S170.

9 Iseki K, Ikemiya Y, Kinjo K, Inoue T, Iseki C, Takishita S: Body mass index and the risk of development of end-stage renal disease in a screened cohort. Kidney Int 2004;65:18701876.

10 Hsu CY, McCulloch CE, Iribarren C, Darbinian J, Go AS: Body mass index and risk for end-stage renal disease. Ann Intern Med 2006; 144:21-28.

11 Chen J, Muntner P, Hamm LL, Jones DW, Batuman V, Fonseca V, Whelton PK, He J: The metabolic syndrome and chronic kidney disease in U.S. adults. Ann Intern Med 2004;140: 167-174.

12 Lea J, Cheek D, Thornley-Brown D, Appel L, Agodoa L, Contreras G, Gassman J, Lash J, Miller ER 3rd, Randall O, Wang X, McClellan W; AASK Study Investigators: Metabolic syndrome, proteinuria, and the risk of progressive CKD in hypertensive African Americans. Am J Kidney Dis 2008;51:732-740.

13 Thomas G, Sehgal AR, Kashyap SR, Srinivas TR, Kirwan JP, Navaneethan SD: Metabolic syndrome and kidney disease: a systematic review and meta-analysis. Clin J Am Soc Nephrol 2011;6:2364-2373.

14 Townsend RR, Anderson AH, Chen J, Gadebegku CA, Feldman HI, Fink JC, Go AS, Joffe M, Nessel LA, Ojo A, Rader DJ, Reilly MP, Teal V, Teff K, Wright JT, Xie D: Metabolic syndrome, components, and cardiovascular disease prevalence in chronic kidney disease: findings from the Chronic Renal Insufficiency Cohort (CRIC) study. Am J Nephrol 2011; 33(6):477-484.

15 Coresh J, Selvin E, Stevens LA, Manzi J, Kusek JW, Eggers P, Van Lente F, Levey AS: Prevalence of chronic kidney disease in the United States. JAMA 2007;298:2038-2047.

16 Praga M, Hernandez E, Morales E, Campos AP, Valero MA, Martinez MA, Leon M: Clinical features and long-term outcome of obesityassociated focal segmental glomerulosclerosis. Nephrol Dial Transplant 2001;16:1790-1798.

17 Amann K, Benz K: Structural renal changes in obesity and diabetes. Semin Nephrol 2013;33: 23-33.

18 Saxena AB, Myers BD, Derby G, Blouch KL, Yan J, Ho B, Tan JC: Adaptive hyperfiltration in the aging kidney after contralateral nephrectomy. Am J Physiol Renal Physiol 2006; 291:F629-F634.

19 Zhuo JL, Li XC: New insights and perspectives on intrarenal renin-angiotensin system: focus on intracrine/intracellular angiotensin II. Peptides 2011;32:1551-1565.

20 Cassis LA, Police SB, Yiannikouris F, Thatcher SE: Local adipose tissue renin-angiotensin system. Curr Hypertens Rep 2008;10:93-98.

21 Henegar JR, Bigler SA, Henegar LK, Tyagi SC, Hall JE: Functional and structural changes in the kidney in the early stages of obesity. J Am Soc Nephrol 2001;12:1211-1217.
22 Chagnac A, Weinstein T, Korzets A, Ramadan E, Hirsch J, Gafter U: Glomerular hemodynamics in severe obesity. Am J Physiol Renal Physiol 2000;278:F817-F822.

23 Hall JE, Brands MW, Dixon WN, Smith MJ Jr: Obesity-induced hypertension. Renal function and systemic hemodynamics. Hypertension 1993;22:292-299.

24 Ribstein J, du Cailar G, Mimran A: Combined renal effects of overweight and hypertension. Hypertension 1995;26:610-615.

25 Thethi T, Kamiyama M, Kobori H: The link between the renin-angiotensin-aldosterone system and renal injury in obesity and the metabolic syndrome. Curr Hypertens Rep 2012;14:160-169.

26 Chagnac A, Weinstein T, Herman M, Hirsh J, Gafter U, Ori Y: The effects of weight loss on renal function in patients with severe obesity. J Am Soc Nephrol 2003;14:1480-1486.

27 Engeli S, Bohnke J, Gorzelniak K, Janke J, Schling P, Bader M, Luft FC, Sharma AM: Weight loss and the renin-angiotensin-aldosterone system. Hypertension 2005;45:356362.

28 Kshirsagar AV, Joy MS, Hogan SL, Falk RJ, Colindres RE: Effect of ACE inhibitors in diabetic and nondiabetic chronic renal disease: a systematic overview of randomized placebocontrolled trials. Am J Kidney Dis 2000;35: 695-707.

29 Chiurchiu C, Remuzzi G, Ruggenenti P: Angiotensin-converting enzyme inhibition and renal protection in nondiabetic patients: the data of the meta-analyses. J Am Soc Nephrol 2005;16(suppl 1):S58-S63.

30 Kunz R, Friedrich C, Wolbers M, Mann JF. Meta-analysis: effect of monotherapy and combination therapy with inhibitors of the renin angiotensin system on proteinuria in renal disease. Ann Intern Med 2008;148:3048.

31 Randomised placebo-controlled trial of effect of ramipril on decline in glomerular filtration rate and risk of terminal renal failure in proteinuric, non-diabetic nephropathy. The GISEN group (Gruppo Italiano di Studi Epidemiologici in Nefrologia). Lancet 1997;349: 1857-1863.

32 Maki DD, Ma JZ, Louis TA, Kasiske BL: Longterm effects of antihypertensive agents on proteinuria and renal function. Arch Intern Med 1995;155:1073-1080.

33 Ahmed SB, Fisher ND, Stevanovic R, Hollenberg NK: Body mass index and angiotensindependent control of the renal circulation in healthy humans. Hypertension 2005; 46: 1316-1320.

34 THIN Data Statistics 2014. http://csdmruk. cegedim.com/ (December 1, 2014).

35 Lewis JD, Bilker WB, Weinstein RB, Strom $\mathrm{BL}$ : The relationship between time since registration and measured incidence rates in the general practice research database. Pharmacoepidemiol Drug Saf 2005; 14:443-451.

36 Levey AS, Stevens LA, Schmid CH, Zhang YL, Castro AF 3rd, Feldman HI, Kusek JW, Egg- ers P, Van Lente F, Greene T, Coresh J; CkdEPI (Chronic Kidney Disease Epidemiology Collaboration): A new equation to estimate glomerular filtration rate. Ann Intern Med 2009;150:604-612.

37 Office for National Statistics: Census, Key Statistics and Quick Statistics for Local Authorities in the United Kingdom - Part 12011. http://www.ons.gov.uk/ons/index.html (cited November 1, 2013).

38 Brenner BM, Cooper ME, de Zeeuw D, Keane WF, Mitch WE, Parving HH, Remuzzi G, Snapinn SM, Zhang Z, Shahinfar S; RENAAL Study Investigators: Effects of losartan on renal and cardiovascular outcomes in patients with type 2 diabetes and nephropathy. $\mathrm{N}$ Engl J Med 2001;345:861-869.

39 Lewis EJ, Hunsicker LG, Clarke WR, Berl T, Pohl MA, Lewis JB, Ritz E, Atkins RC, Rohde R, Raz I; Collaborative Study Group: Renoprotective effect of the angiotensin-receptor antagonist irbesartan in patients with nephropathy due to type 2 diabetes. $\mathrm{N}$ Engl J Med 2001;345:851-860.

40 Townsend P: Poverty in the United Kingdom. London, Allen Lane and Penguin Books, 1979.

41 Chirinos JA, Franklin SS, Townsend RR, Raij L: Body mass index and hypertension hemodynamic subtypes in the adult US population. Arch Intern Med 2009;169:580-586.

42 De Nicola L, Gabbai FB, Agarwal R, Chiodini P, Borrelli S, Bellizzi V, Nappi F, Conte G, Minutolo R: Prevalence and prognostic role of resistant hypertension in chronic kidney disease patients. J Am Coll Cardiol 2013;61: 2461-2467.

43 De Nicola L, Borrelli S, Gabbai FB, Chiodini P, Zamboli P, Iodice C, Vitiello S, Conte G, Minutolo R: Burden of resistant hypertension in hypertensive patients with non-dialysis chronic kidney disease. Kidney Blood Press Res 2011;34:58-67.

44 Hirata A, Maeda N, Hiuge A, Hibuse T, Fujita K, Okada T, Kihara S, Funahashi T, Shimomura I: Blockade of mineralocorticoid receptor reverses adipocyte dysfunction and insulin resistance in obese mice. Cardiovasc Res 2009;84:164-172.

45 Hirata A, Maeda N, Nakatsuji H, Hiuge-Shimizu A, Okada T, Funahashi T, Shimomura I: Contribution of glucocorticoid-mineralocorticoid receptor pathway on the obesity-related adipocyte dysfunction. Biochem Biophys Res Commun 2012;419:182-187.

46 Ingelsson E, Pencina MJ, Tofler GH, Benjamin EJ, Lanier KJ, Jacques PF, Fox CS, Meigs JB, Levy D, Larson MG, Selhub J, D’Agostino RB Sr, Wang TJ, Vasan RS: Multimarker approach to evaluate the incidence of the metabolic syndrome and longitudinal changes in metabolic risk factors: the Framingham offspring study. Circulation 2007;116:984-992.

47 de Paula RB, da Silva AA, Hall JE: Aldosterone antagonism attenuates obesity-induced hypertension and glomerular hyperfiltration. Hypertension 2004;43:41-47. 
48 Anderson AH, Yang W, Townsend RR, Pan Q, Chertow GM, Kusek JW, Charleston J, He J, Kallem R, Lash JP, Miller ER 3rd, Rahman M, Steigerwalt S, Weir M, Wright JT Jr, Feldman HI; Chronic Renal Insufficiency Cohort Study Investigators: Time-updated systolic blood pressure and the progression of chronic kidney disease: a cohort study. Ann Intern Med 2015;162:258-265.

49 Kovesdy CP, Lu JL, Molnar MZ, Ma JZ, Canada RB, Streja E, Kalantar-Zadeh K, Bleyer AJ: Observational modeling of strict vs conventional blood pressure control in patients with chronic kidney disease. JAMA Intern Med 2014;174:1442-1449.

50 Levey AS, de Jong PE, Coresh J, El Nahas M, Astor BC, Matsushita K, Gansevoort RT, Kasiske BL, Eckardt KU: The definition, classification, and prognosis of chronic kidney disease: a KDIGO controversies conference report. Kidney Int 2011;80:17-28.

51 Haller H, Ito S, Izzo JL Jr, Januszewicz A, Katayama S, Menne J, Mimran A, Rabelink TJ, Ritz E, Ruilope LM, Rump LC, Viberti G; ROADMAP Trial Investigators: Olmesartan for the delay or prevention of microalbuminuria in type 2 diabetes. N Engl J Med 2011;364: 907-917.

52 Andraws R, Brown DL: Effect of inhibition of the renin-angiotensin system on development of type 2 diabetes mellitus (meta-analysis of randomized trials). Am J Cardiol 2007; 99:1006-1012.

53 Kaplan EL, Meier P: Nonparametric estimation from incomplete observations. J Am Statist Assoc 1958;53:457-481.
54 Joffe MM, Ten Have TR, Feldman HI, Kimmel SE: Model selection, confounder control, and marginal structural models: review and new applications. Am Stat 2004;58:272-279.

55 Robins JM, Hernan MA, Brumback B: Marginal structural models and causal inference in epidemiology. Epidemiology 2000;11:550560.

56 Cole SR, Hernán MA: Constructing inverse probability weights for marginal structural models. Am J Epidemiol 2008;168:656-664.

57 Gilg J, Pruthi R, Fogarty D: UK renal registry 17th annual report: chapter 1 UK renal replacement therapy incidence in 2013: national and centre-specific analyses. Nephron 2015;129(suppl 1):1-29.

58 Wright JT Jr, Bakris G, Greene T, Agodoa LY, Appel LJ, Charleston J, Cheek D, Douglas-Baltimore JG, Gassman J, Glassock R, Hebert L, Jamerson K, Lewis J, Phillips RA, Toto RD, Middleton JP, Rostand SG; African American Study of Kidney Disease and Hypertension Study Group: Effect of blood pressure lowering and antihypertensive drug class on progression of hypertensive kidney disease: results from the AASK trial. JAMA 2002;288:2421-2431.

59 Bakris GL, Weir MR: Angiotensin-converting enzyme inhibitor-associated elevations in serum creatinine: is this a cause for concern? Arch Intern Med 2000;160:685-693.

60 Jun M, Turin TC, Woodward M, Perkovic V, Lambers Heerspink HJ, Manns BJ, Tonelli M, Hemmelgarn BR: Assessing the validity of surrogate outcomes for ESRD: a meta-analysis. J Am Soc Nephrol 2015;26:2289-2302.
61 Mallamaci F, Ruggenenti P, Perna A, Leonardis D, Tripepi R, Tripepi G, Remuzzi G, Zoccali C; REIN Study Group: ACE inhibition is renoprotective among obese patients with proteinuria. J Am Soc Nephrol 2011;22:11221128.

62 Alicic R, Tuttle KR: Do agents that block the RAS truly offer renoprotective effects in early stage, nonproteinuric nephropathy? Curr Hypertens Rep 2007;9:393-402.

63 Delanaye P, Mariat C: The applicability of eGFR equations to different populations. Nat Rev Nephrol 2013;9:513-522.

64 Delanaye P, Krzesinski JM: Indexing of renal function parameters by body surface area: intelligence or folly? Nephron Clin Pract 2011; 119:c289-c292.

65 Eriksen BO, Melsom T, Mathisen UD, Jenssen TG, Solbu MD, Toft I: GFR normalized to total body water allows comparisons across genders and body sizes. J Am Soc Nephrol 2011;22:1517-1525.

66 Bouquegneau A, Vidal-Petiot E, Vrtovsnik F, Cavalier E, Rorive M, Krzesinski JM, Delanaye $\mathrm{P}$, Flamant M: Modification of diet in renal disease versus chronic kidney disease epidemiology collaboration equation to estimate glomerular filtration rate in obese patients. Nephrol Dial Transplant 2013;28(suppl 4):iv122-iv130.

67 Kidney Disease: Improving Global Outcomes (KDIGO) CKD Work Group: KDIGO 2012 clinical practice guideline for the evaluation and management of chronic kidney disease. Kidney Inter Suppl 2013;3:1-150. 